\title{
Survey of Accredited Calibration Laboratories in Indonesia to Ensure Metrological Traceability Based on Iso/Iec 17025:2017 (Case Study: Gauge Block Cali- bration Service)
}

\author{
Muhammad Haekal Habibie ${ }^{1,2}$, Ocka Hedrony ${ }^{1,2}$ \\ ${ }^{1}$ Center for Research and Human Resource Development, National Standardization Agency of Indonesia, Tan- \\ gerang Selatan, Banten, 15314, Indonesia. \\ ${ }^{2}$ National Measurement Standards (SNSU), National Standardization Agency of Indonesia, Tangerang Selatan, \\ Banten, 15314, Indonesia. \\ *Corresponding author. Email:tiwi@bsn.go.id
}

\begin{abstract}
One of the actors managing national quality infrastructure in Indonesia is accredited calibration laboratory that regulates the strategic role of facilitating trade activities. Metrological traceability of accredited calibration laboratory is an inherent entity, which determines the validity of calibration result. In the context of activities based on ISO/IEC 17025:2017 standard, metrological traceability is the most fundamental and much needed element. Therefore, it is necessary to survey the accredited calibration laboratory as respondents of investigation to know the condition of metrological traceability in Indonesia. The survey was conducted using questionnaire for the respondents. The limitation of the investigation was carried out by selecting respondents who had gauge block calibration services. From the survey results, it was found that the majority of the metrological traceability of the respondents was obtained from SNSU-BSN which is the National Metrology Institute (NMI) in Indonesia and also from the private calibration laboratory. SNSU-BSN as NMI in Indonesia has carried out its role as a gauge block calibration service provider and oversees metrological traceability on a national scale.
\end{abstract}

Keywords: Laboratory Calibration, Gauge Block, Metrological Traceability, Survey accreditation.

\section{INTRODUCTION}

The national quality infrastructure (NQI) is the institutional framework that establishes and implements standardization (including conformity assessment services), metrology, and accreditation [1]. Standardization body has duties in terms of design, making, authorization, implementation, amendment and withdrawal of technical standards. The accreditation body has the task to conduct conformity assessment of products or services to meet certain reference standards. While the National Metrology Institute is tasked with maintaining primary/secondary standards in order to disseminate the measurement value to standards/measuring instruments that have lower precision in order to create metrological traceability in a country. Implementation of the national quality infrastructure (NQI) has been widely carried out in various countries.

In the concept of implementing national quality infrastructure (NQI) in Indonesia, accredited calibration laboratories play a strategic role in facilitating trade activities. For examples in the health sector, blood pressure gauges (sphygmomanometer) used to measure blood pressure need to be calibrated to find out the deviation value of device. It would be very risky if the actual display value of blood pressure gauges (sphygmomanometer) is wrong, because it will cause a misdiagnosis of the patient and an effect on the error of the dosage and medication. In the commerce field, the flow meter at the gas station also needs to be calibrated. This is to ensure that the value of the amount 
shown in the indicator at the gas station is in accordance with the value of the amount of fuel that goes to the tank of vehicle. Another case that related to aircraft industry activity, the bolts attached to the fuselage must not be easily come off and shake. Therefore, the bolts and threads must be made with a precise size. So that the bolt and thread can be precise, it is necessary to measure with calibrated length measuring device on scheduled basis.

In this investigation, the object of investigation is accredited calibration laboratories by the National Accreditation Committee in Indonesia (KAN). In implementation of ISO/IEC 17025:2017 for accredited calibration laboratories, one of the important factors is metrological traceability [2]. Metrological traceability is inherent entity, which determines the validity calibration result. Because of that, some survey activities were carried out to the accredited calibration laboratories as respondents to know the current condition of their metrological traceability. Limitation of this investigation is selected the accredited calibration laboratories that have length measurement scopes, especially for gauge block calibration services.

\section{METHODS}

In this investigation, the method for collecting the primary data to find information about the metrological traceability of the calibration laboratory is by conducting a survey of respondents using an investigation questionnaire. Respondents in this investigation came from calibration laboratories that have dimensional calibration services and have been accredited by the National Accreditation Committee (KAN). The questions on the questionnaire are related to the respondent's gauge block and its traceability history.

The questions on questionnaire consist of ownership of the measuring block standard, size and type of gauge block, their calibration customers, and schedule of calibration activity of the gauge block. This information is useful to find out information about the metrological traceability of respondents. Respondents data such as company name, company address, contact person and email address were obtained from the KAN website (kan.or.id).

\section{RESULTS AND DISCUSSION}

From the survey results, obtained data from 51 respondents (accredited calibration laboratory) who filled out the questionnaire. The first data obtained from questionnaires that have been filled out by respondents is about the ownership of the gauge block standard. The survey results regarding this question are as shown in Figure 1.

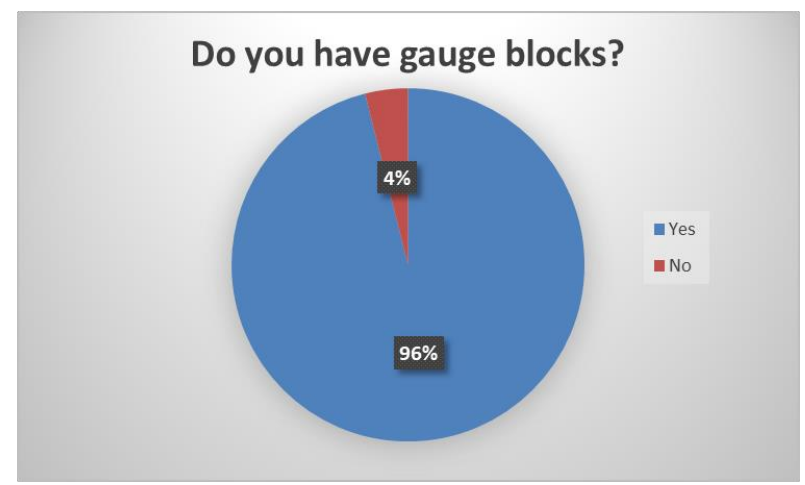

Figure 1. Survey result on question regarding ownership of gauge block.

From 51 respondents, 49 respondents (96\%) had gauge block standards, while 2 respondents (4\%) did not have gauge block standards. In addition, from 2 respondents who did not have gauge block standards, one of them conducted gauge block calibration services for external customers. It can be said that one of the calibration service providers conducted calibrations without a gauge block even though the service was specifically intended to use it. From this fact, it can be said that the majority of respondents have gauge block standards to conduct business processes in the form of calibration services for customers, both internal and external customers.

The gauge block standard is needed as main equipment for respondents to perform services to the customer. Based on its type, gauge block consists of 2 types that are divided based on the measuring range. The first type is the short gauge block (GB) with a measuring range from $0.5 \mathrm{~mm}$ to $100 \mathrm{~mm}$. The second type is the long gauge block (GB) with a measuring range from $125 \mathrm{~mm}$ to $1000 \mathrm{~mm}$. The type of gauge block owned by the respondent is one of the questions asked in the questionnaire. The survey results regarding this question are as shown in Figure 2. 


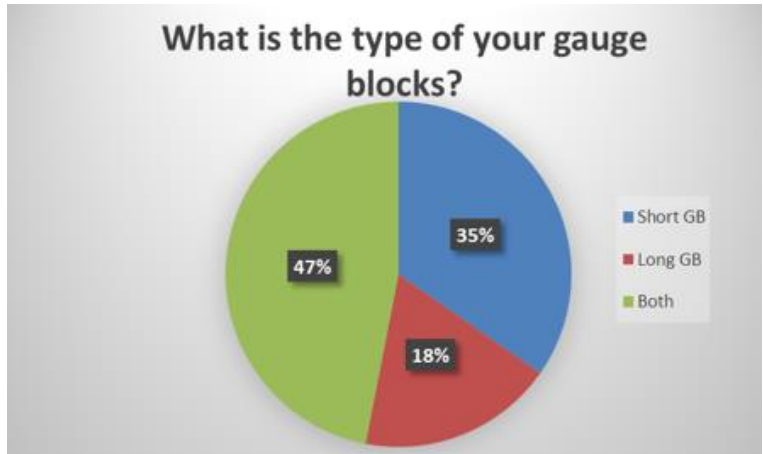

Figure 2. Survey result on question the type of gauge block.

As many as 49 out of 51 respondents who have gauge block standards, 17 respondents (35\%) have gauge block with the type of short GB, 9 respondents (18\%) have gauge blocks with the type of long GB, and 23 respondents $(47 \%)$ have both types. From the survey results regarding the type of gauge block owned by respondent, it means that most respondents have both types of gauge block. The ownership of gauge blocks for both types can expand or widen the scope of the calibration scope that can be offered to customers through calibration services. In addition, there are differences in Unit Under Test (UUT) which can be calibrated by short GB and long GB so that the calibration scope is not related to each other.

The gauge block standard owned by respondents needs to be calibrated periodically. According to clause 6.4 .6 of ISO/IEC 17025:2017 [6], it states that the Laboratory shall establish a calibration program, which shall be reviewed and adjusted as necessary in order to maintain confidence in the status of calibration. In addition, according to clause 6.4 .6 of ISO/IEC 17025:2017, measuring equipment shall be calibrated when calibration of the equipment is required to establish the metrological traceability of the reported results. In this case, it can be interpreted that, the traceability of the gauge block can be documented by its calibration to a standard higher on the traceability pyramid. Related to this investigation activity, the investigation questionnaire was asked about the calibration activities carried out by respondents. The investigation team asked whether the gauge block standard of the respondent was calibrated before its expired date. The survey results regarding this question are as shown in Figure 3.

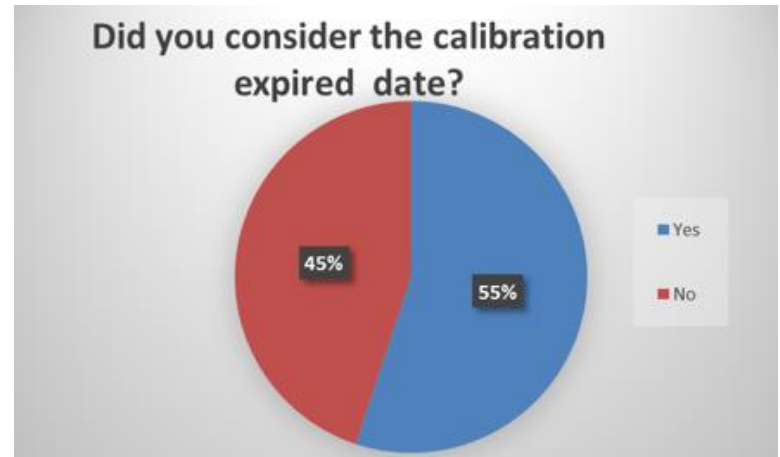

Figure 3. Survey result on question regarding consideration of calibration expired date.

From 49 respondents who had a gauge block standard, 27 respondents $(55 \%)$ carried out calibration of the gauge block by taking into account the calibration expired date. This means that the respondent believes that the calibration period of the gauge block standard has never exceeded the expired date. In addition, 22 respondents $(45 \%)$ had carried out calibration activities when the calibration expired date had passed. When the calibration expired date period has passed the deadline, what needs to be done is to carry out intra-laboratory comparison activities such as intermediate checks to see whether the performance of the equipment (gauge block standard) is still within in the specifications of the equipment or out of specification. When the equipment (gauge block standard) performance is still within specifications, it is still suitable for use in performing calibration services to the customer. Meanwhile, when the performance of the equipment (gauge block standard) is beyond its specifications, it can be said that action needs to be taken to prevent the use of the equipment to perform calibration services. Then it is necessary to re-calibrate the equipment (gauge block standard) whose performance is outside the specifications to detect the deviations from its specifications.

In the calibration activity, metrological traceability is the most fundamental and indispensable element. According to clause 6.5 on the ISO/IEC 17025:2017 standard [6], one of the metrological traceability is obtained from calibration activities against standards/measuring instruments with a competent calibration laboratory. The calibration laboratory can be considered competent, among others, it can be seen from its credibility such as having a calibration scope that has been accredited by an accreditation body, having a calibration scope with a small measurement uncer- 
tainty value, having experience in carrying out calibration services for a long period of time, as well as having trained technical personnel and experienced. In connection with this investigation activity, we asked to the respondent about the destination calibration laboratory which was calibrate their gauge block standard. The survey results regarding this question are as shown in Figure 4.

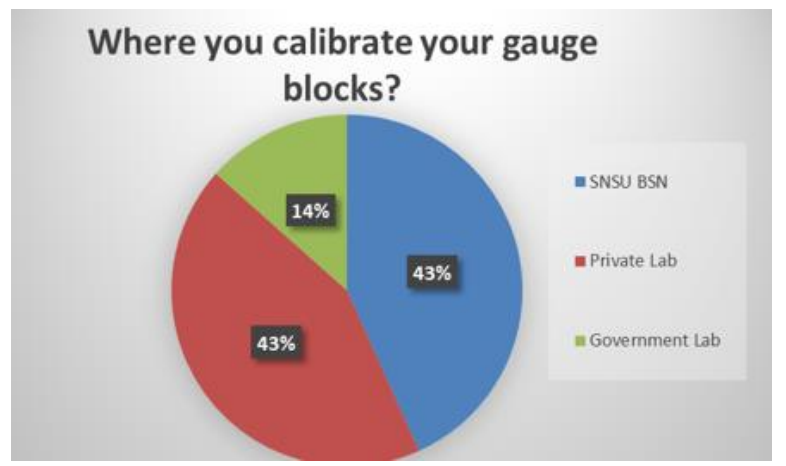

Figure 4. Survey result on question regarding the places of calibration destination

From the 49 respondents who have gauge block standards, 29 respondents (43\%) calibrate their gauge block standards to the SNSU-BSN, 29 respondents (43\%) conduct their calibration gauge block calibrations to the private calibration laboratory, and as many as 9 respondents (14\%) carried out calibration activities to government calibration laboratories. From the survey results of the calibration destination laboratory, the majority of respondents conducted calibration activities to the SNSU-BSN. This is function of the SNSU-BSN as National Metrology Institute (NMI) that disseminates the measurement results of primary/secondary standards and maintains the metrological traceability in Indonesia. In addition, the majority of respondents also conduct calibration activities to private calibration laboratories. This is positive progress in the business regarding calibration activity, where there is a lot of participation from the private sector. In addition, the quality of private calibration laboratories can be improved by applying ISO/IEC 17025: 2017 standard consistently and continuously so as to generate trust from customers who perform the calibration.

\section{CONCLUSION}

From the results of this investigation, it can be concluded that as many as $96 \%$ of respondents (accredited calibration laboratory) have gauge block standard to carry out calibration service activities. From the respondents who have the gauge block, $47 \%$ of respondents have short gauge block and long gauge block, $35 \%$ of respondents only have short gauge block, and as many as $18 \%$ of respondents only have long gauge block. Regarding awareness of the calibration activities, as many as $55 \%$ of respondents consider the calibration expired date of the gauge block standard they have. Besides that, the majority of respondents (accredited calibration laboratory), calibrate their gauge block standard to SNSU-BSN or to private calibration laboratory with the same percentage of $43 \%$. SNSUBSN as National Metrology Institute (NMI) in Indonesia has performed its role as calibration service provider to oversee national scale metrological traceability. In addition, the role of a private calibration laboratory is also very necessary to serve the demand for calibration orders which are always increasing every year. The rise of participation from the private sector is also marked by the growth of accredited calibration laboratories that increase every year. In the concept of metrological traceability, calibration laboratories conducting calibration activities to reference laboratories such as SNSU-BSN are intended to obtain metrological traceability. So that the expanded uncertainty obtained from the calibration certificate is used as component in the measurement uncertainty of their equipment.

\section{ACKNOWLEDGMENT}

We are deeply grateful to Center for Investigation and Human Resource Development - BSN, National Measurement Standards (SNSU) - BSN, and all of respondents that gave us support in this investigation.

\section{REFERENCES}

[1] Tippmen C and Racine J L 2013 The National Quality Infrasctructure A Tool for Competitiveness, Trade, and Social Well-being (Washington: The World Bank).

[2] Trishch R, Maletska O, Cherniak O, Semionova J, and Jancis V 2020 Analysis of the Requirements of International and National Standards for Measurement Methods and Metrological Equipment Innovative Technologies and Scientific Solutions for Industries $1(11)$

[3] International Organization for Standardization 1998 ISO 3650:1998 Geometrical Product Specifications (GPS) - Length Standards - Gauge Blocks (Switzerland: ISO)

[4] Joint Committee for Guides in Metrology 2012 
JCGM 200:2012 International Vocabulary of Metrology - Basic and General Concept and Associated Terms (VIM) (France: JCGM)

[5] Precidential Decree Number 4 Year 2018 about National Standardization Agency of Indonesia (BSN)

[6] International Organization for Standardization 2017 ISO/IEC 17025:2017 General Requirements for the Competence of Testing and Calibration Laboratories (Switzerland: ISO. 